\title{
Adenosine triphosphate and hemoglobin in vasospastic monkeys
}

\section{R. Loch Macdonald, M.D., Ph.D., Bryce Weir, M.D., John Zhang, M.D., Ph.D., Linda S. Marton, Ph.D., Michael Sajdak, B.A., and Lydia M. Johns}

Section of Neurosurgery, University of Chicago Medical Center, Chicago, Illinois

Adenosine triphosphate (ATP) is a vasoactive compound found in high levels inside erythrocytes that may contribute to vasospasm occurring after subarachnoid hemorrhage (SAH). This study was instituted to test whether ATP causes vasospasm in a monkey model.

Thirty-two monkeys were randomized to four groups of eight monkeys each to undergo cerebral angiography at baseline (Day 0) and then at Day 7 after subarachnoid placement of: 1) agarose, 2) ATP in agarose, 3) autologous hemolysate in agarose, or 4) purified human hemoglobin $\mathrm{A}_{0}$ in agarose. Vasospasm was assessed by comparison of Day 0 and Day 7 angiograms between and within groups and by pathological examination of a subset of perfusion-fixed monkeys. Levels of adenine nucleotides were measured on Day 7 in subarachnoid agarose by high-pressure liquid chromatography.

There was significant vasospasm of the right middle cerebral artery in groups given ATP $(-28 \pm 7 \%$ reduction, paired t-test, $\mathrm{p}<0.05)$, hemolysate $(-23 \pm 7 \%, \mathrm{p}<0.05)$, or pure hemoglobin $(-15 \pm 2 \%, \mathrm{p}<$ $0.005)$. Analysis of variance revealed no significant differences between groups in diameters of cerebral arteries on Day 7. Pathological examination showed mild inflammation in the subarachnoid spaces of animals exposed to hemolysate or hemoglobin and less inflammation in those given ATP or agarose. There were no pathological changes in the cerebral arteries of animals in any group. Most of the ATP diffused out of the subarachnoid agarose by Day 7, and levels of adenine nucleotides in subarachnoid agarose were higher on Day 7 in animals exposed to hemoglobin or hemolysate.

It is concluded that ATP could contribute to vasospasm occurring after SAH but that further investigations are necessary to determine if levels of ATP adjacent to vasospastic arteries are sufficient to contribute to vasospasm. In addition, no observation was made of severe vasospasm with histopathological changes in the arteries equivalent to that produced by whole blood clot in the subarachnoid space of monkeys. It should be determined whether this is because a single compound, such as ATP or hemoglobin, causes vasospasm, but that placing the compound in agarose alters its delivery and decreases the amount of vasospasm produced, or whether vasospasm is a more complex, multifactorial process.

Key Words * adenosine triphosphate * hemoglobin * subarachnoid hemorrhage * vasospasm * cynomolgus monkey

A key process in the pathogenesis of vasospasm is believed to be hemolysis with release of erythrocytic cytosol into the subarachnoid space.[8] Several lines of evidence suggest that oxyhemoglobin (OxyHb) or a related high-molecular-weight compound is the substance in erythrocytic cytosol that causes vasospasm. 
Although studies showed vasospasm could be produced by injection or placement of hemoglobin into the subarachnoid space of monkeys, severe vasospasm was not reliably produced.[9,10] In addition, it was recognized that the hemoglobin solutions used in some studies were not pure and contained other potentially vasoactive substances such as phospholipids, other stromal proteins, and endotoxin and that preparation methods may have produced vasoactive or toxic breakdown products that are different from those produced in vivo.[3] Magnetic resonance imaging studies also found that OxyHb disappeared from intracerebral hematomas within hours.[6] Furthermore, when fresh erythrocytic cytosol or hemolysate was applied to rat basilar artery smooth-muscle cells, an increase in $\left[\mathrm{Ca}^{++}\right]_{\mathrm{i}}$ occurred, and this was found to be mediated by adenosine triphosphate (ATP) and not hemoglobin.[25] The second most abundant substance within the erythrocyte is ATP.[24] These findings suggested a need to reevaluate the hypothesis that OxyHb alone causes vasospasm. In this experiment, pure ATP or pure hemoglobin was placed in the subarachnoid spaces of monkeys in amounts found in a volume of blood clot known to produce severe vasospasm reliably. $[9,10]$ The carrier substance by itself (agarose) was used as a negative control. Because prior work suggested that erythrocytic cytosol contains all of the activity necessary to produce severe vasospasm, autologous hemolysate was used as a positive control.

\section{CLINICAL MATERIAL AND METHODS}

\section{Study Protocol}

Thirty-two cynomolgus monkeys (Macaca fascicularis) were randomly allocated to one of four groups of eight monkeys. The surgeon was blind to the monkey's group identity until after the arachnoid dissection was made, at which time the agarose was delivered for implantation. Blinding was not possible after this point because of the difference in color of the compounds used. An investigator who was blinded to the monkeys' group identity interpreted the angiograms and performed data analysis. On the first day (Day 0), the animals underwent cerebral angiography and placement of one of the following compounds in the subarachnoid space next to the cerebral arteries: 1) agarose, 2) ATP in agarose, 3) autologous hemolysate in agarose, or 4) purified human hemoglobin $\mathrm{A}_{0}$ in agarose. Seven days after placement of the subarachnoid compounds (Day 7), the animals underwent repeated angiography and were killed. The remaining subarachnoid compounds were removed for measurement of adenine nucleotide levels. Two animals in each group were perfusion fixed on Day 7 for histopathological examination of the brain and cerebral arteries.

All procedures performed in the animals were approved by the Animal Care and Use Committee of the University of Chicago, and they complied with standards set by the United States Department of Health and Human Services.

\section{Angiography and Subarachnoid Compound Placement}

Angiography, craniotomy, and subarachnoid agarose placement were performed as described previously.[7,9,10] On Day 0, animals were sedated with an intramuscular injection of ketamine (6-10 $\mathrm{mg} / \mathrm{kg}$ ), intubated, and ventilated while receiving 1 to $2 \%$ isofluorane. The animal's body temperature, $\mathrm{PaCO}_{2}$ and $\mathrm{PaO}_{2}$, blood pressure, and heart rate were monitored. A catheter was inserted into the right axillary artery and a baseline was obtained. Constant magnification and exposure were used. An intravenous injection of Mannitol $(0.5 \mathrm{~g} / \mathrm{kg})$ was given, the $\mathrm{PaCO}_{2}$ was adjusted to $30 \mathrm{~mm} \mathrm{Hg}$, and a right frontotemporal craniectomy was performed. The arachnoid membrane was dissected from the right internal carotid artery (ICA), middle cerebral artery (MCA), and anterior cerebral artery (ACA). The agarose was placed next to the arteries and the wound was closed in layers. 
Low melting-point agarose was used, as previously described,[9] to create a clotlike substance that contains and slowly releases various compounds. Disodium ATP $(5 \mathrm{mg})$ and pure ferrous human hemoglobin $\mathrm{A}_{0}(600$ $\mathrm{mg}$ ) were used in amounts found in $5 \mathrm{ml}$ of monkey blood. The hemoglobin was ultrapure, uncross-linked, and of adequate purity to be used in humans. The final concentrations of ATP and ferrous hemoglobin in the subarachnoid agarose were $1.6 \mathrm{mmol} / \mathrm{L}$ and $1.9 \mathrm{mmol} / \mathrm{L}$, respectively. The concentration of ferrous hemoglobin in monkey blood was $120 \pm 3 \mathrm{~g} / \mathrm{L}(1.9 \pm 0.1 \mathrm{mmol} / \mathrm{L}, 12$ samples $)$. Autologous hemolysate was prepared 3 days prior to the animal undergoing craniectomy, as previously reported.[12,25] The washed erythrocytes were lysed in hypotonic saline followed by centrifugation to remove the membrane fraction and concentration was restored to the original volume by vacuum drying. Thus, this group received the amount of hemolysate and ferrous hemoglobin $(2 \pm 0.2 \mathrm{mmol} / \mathrm{L}$, six samples) found in $5 \mathrm{ml}$ of monkey blood. Some ATP was lost during preparation of hemolysate so the concentration of ATP in hemolysate was $120 \pm 26$ $\mu \mathrm{mol} / \mathrm{L}$, which is approximately 10 -fold lower than that used in the ATP group.

\section{Day 7 Angiography and Pathological Examination}

After 7 days, angiography was repeated while the animals were receiving general anesthetic, as described previously. While still anesthetized, the monkeys were exsanguinated, and their brains were removed. The remaining subarachnoid agarose was carefully removed to avoid contamination with fresh blood and stored in liquid nitrogen for measurement of adenine nucleotide levels. In two animals in each group the chest was opened, the left ventricle catheterized, the descending aorta occluded, and the right atrium opened; they were then perfused with $500 \mathrm{ml} 0.9 \% \mathrm{NaCl}$ followed by $500 \mathrm{ml} \mathrm{10 \%} \mathrm{buffered} \mathrm{formalin.} \mathrm{The} \mathrm{brains} \mathrm{were} \mathrm{removed}$ and fixed in $10 \%$ buffered formalin for 1 week. Hematoxylin and eosin-stained histological sections of the right (clot) and left (control) sides of the brain and MCA were studied for evidence of inflammation and other histopathological features. Inflammation was indicated by the presence of polymorphonuclear or mononuclear lymphocytes and macrophages. Inflammation was assessed in the subarachnoid space of the sylvian fissure in the area where the agarose was placed and in the periarterial and adventitial area of the MCAs. The degree of inflammation was graded on a 3-point scale by an investigator blinded to the animal's group.

\section{Measurement of Adenine Nucleotide Concentrations}

Concentrations of ATP, adenosine diphosphate (ADP), and adenosine monophosphate (AMP) in the remaining subarachnoid agaroses were determined by high-performance liquid chromatography.[25] The samples were weighed, thawed, and rapidly treated with cold $0.9 \mathrm{M}$ perchloric acid. They were then homogenized and centrifuged, and the supernatant fluid was neutralized with $2 \mathrm{M} \mathrm{KOH}$. Separation was achieved on a 3- $\mu \mathrm{m} \mathrm{C} 18$ column by isocratic elution with $0.15 \mathrm{M} \mathrm{KH}_{2} \mathrm{PO}_{4}$ and $0.15 \mathrm{M} \mathrm{KCl}$, adjusted to $\mathrm{pH} 6$ with $\mathrm{KOH}$.

\section{Statistical Analysis}

An optical micrometer was used to measure cerebral arterial diameters at predetermined points along the extradural ICA, intradural ICA, ACA, MCA, and basilar artery (BA). Vasospasm was assessed within groups by comparing angiograms obtained before and 7 days after agarose placement. Vasospasm was classified as none $(<10 \%$ reduction in diameter), mild $(10-25 \%$ reduction), moderate $(26-50 \%$ reduction), or severe $(>50 \%$ reduction). Comparisons within groups across time were made by paired t-test. Comparisons between groups at Day 0 and Day 7 were by one-way analysis of variance (ANOVA) followed by a Bonferroni multiple comparison test, if significant variance was found. Vasospasm, assessed using the categorical scale described above, and inflammation were compared between groups at Day 7 by Fisher's exact test. Probability values of less than 0.05 were considered significant. Values are means plus or minus standard error of the means. 


\section{Sources of Supplies and Equipment}

Sigma Chemical Co. (St. Louis, MO) supplied the disodium ATP. The ferrous human hemoglobin used in the preparation of subarachnoid compounds was a gift from Hemosol (Toronto, ON Canada).

The ventilator used was supplied by Harvard Apparatus (Millis, MA). During angiography and compound placement the following monitoring systems were used: for body temperature, Yellow Springs model 43TA (Yellow Springs, OH); for arterial pressures, the STAT profile 3 analyzer from Nova Biomedical (Waltham, MA); for blood pressure, the neonatal vital signs monitor, model 847XT, from Criticon Dynamap (Tampa, FL); and for heart rate, the Nellcor pulse oximeter (Hayward, CA).

\begin{tabular}{|c|c|c|c|c|c|c|c|c|}
\hline \multirow[b]{3}{*}{ Variatle } & \multicolumn{8}{|c|}{$\begin{array}{c}\text { TABLE } 1 \\
\text { PHYSOLOGICAL YARMBLES AT DAV } 0 \text { AND DAV } 7 \text { FOR EACH GROUP OF MONKEVS* }\end{array}$} \\
\hline & \multicolumn{2}{|c|}{$\begin{array}{l}\text { Agarose Group } \\
\text { (8 morkeys) }\end{array}$} & \multicolumn{2}{|c|}{$\begin{array}{l}\text { ATP Group } \\
\text { (7 morkeys) }\end{array}$} & \multicolumn{2}{|c|}{$\begin{array}{c}\text { Hemolysate Group } \\
\text { (8 morkeys] }\end{array}$} & \multicolumn{2}{|c|}{$\begin{array}{c}\text { Hemogobin Group } \\
\text { (8 morkeys) }\end{array}$} \\
\hline & $\overline{\text { Day } 0}$ & Day 7 & Day 0 & Day 7 & $\overline{\text { Day } 0}$ & Day 7 & $\overline{\text { Day } 0}$ & Day 7 \\
\hline $\begin{array}{l}\text { meight }(\mathrm{kg}) \\
\text { heart rate } \\
\text { (beats thin) }\end{array}$ & $\begin{aligned} 4 & \pm 0.2 \\
121 & \pm 6\end{aligned}$ & $\begin{aligned} 4 & \pm 0.2 \\
143 & \pm 8 \ddagger\end{aligned}$ & $\begin{aligned} 3.8 & \pm 0.2 \\
120 & \pm 5\end{aligned}$ & $\begin{aligned} 3.7 & \pm 0.1 \\
138 & \pm 4 \dagger\end{aligned}$ & $\begin{aligned} 4.1 & \pm 0.2 \\
105 & \pm 15\end{aligned}$ & $\begin{aligned} 3.9 & \pm 0.2 \ddagger \\
137 & \pm 8\end{aligned}$ & $\begin{aligned} 3.8 & \pm 0.1 \\
125 & \pm 3\end{aligned}$ & $\begin{array}{l}3.7 \pm 0.1 \\
133 \pm 7\end{array}$ \\
\hline $\begin{array}{l}\text { mean bp } \\
(\mathrm{mm} H \mathrm{H})\end{array}$ & $44 \pm 4$ & $43 \pm 5$ & $40 \pm 3$ & $41 \pm 11$ & $42 \pm 4$ & $38 \pm 3$ & $50 \pm 8$ & $35 \pm 5$ \\
\hline $\begin{array}{l}\mathrm{PaCO}_{2} \\
(\mathrm{~mm} \mathrm{Hg})\end{array}$ & $37 \pm 2$ & $41 \pm 3$ & $42 \pm 3$ & $38 \pm 4$ & $37 \pm 2$ & $37 \pm 2$ & $40 \pm 3$ & $37 \pm 2$ \\
\hline $\begin{array}{l}\text { temperature } \\
\text { ("C) }\end{array}$ & $34 \pm 1$ & $35 \pm 1$ & $35 \pm 1$ & $35 \pm 1$ & $35 \pm 1$ & $34 \pm 1$ & $35 \pm 1$ & $35 \pm 1$ \\
\hline
\end{tabular}

\section{RESULTS}

\section{Physiological Evaluation}

One animal given ATP died immediately after surgery on Day 0. All other animals remained healthy. There were no significant differences in physiological variables between groups when compared at Day 0 or Day 7 (Table 1). Within the groups, animals exposed to agarose or ATP had significantly increased heart rates on Day 7 compared with Day 0, and animals exposed to hemolysate had a significant decrease in weight from Day 0 to Day 7. None of these changes altered angiographically visualized arterial diameters. 
ANGIOGRAPHIC ARTERIAL DIAMETERS AT DAN 0 AND DAV 7 FOR EACH GROUP*

\begin{tabular}{|c|c|c|c|c|c|c|c|c|}
\hline \multirow[b]{2}{*}{ Astery } & \multicolumn{2}{|c|}{ Agarose Group } & \multicolumn{2}{|c|}{ AT P Group } & \multicolumn{2}{|c|}{ Hemolysate Group } & \multicolumn{2}{|c|}{ Hemogobin Group } \\
\hline & Dayo 0 & Day 7 & Day 0 & Day 7 & Day 0 & Day 7 & Day 0 & Day 7 \\
\hline $\begin{array}{l}\text { right } \\
\mathrm{C}_{3} \\
\mathrm{C}_{4} \\
\mathrm{ACA} \\
\text { MCA } \\
\text { left }\end{array}$ & $\begin{array}{l}2.38 \pm 0.10 \\
2.04 \pm 0.10 \\
1.11 \pm 0.11 \\
1.51 \pm 0.09\end{array}$ & $\begin{array}{l}2.37 \pm 0.16 \\
1.88 \pm 0.15 \\
1.07 \pm 0.10 \\
1.40 \pm 0.10\end{array}$ & $\begin{array}{l}2.46 \pm 0.14 \\
2.05 \pm 0.13 \\
1.25 \pm 0.06 \\
1.62 \pm 0.13\end{array}$ & $\begin{array}{l}2.36 \pm 0.11 \\
1.72 \pm 0.13 \dagger \\
1.07 \pm 0.05 \dagger \\
1.14 \pm 0.09 \ddagger\end{array}$ & $\begin{array}{l}2.11 \pm 0.10 \\
1.98 \pm 0.11 \\
1.07 \pm 0.13 \\
1.59 \pm 0.07\end{array}$ & $\begin{array}{l}2.16 \pm 0.06 \\
1.51 \pm 0.13 \dagger \\
0.79 \pm 0.08 \dagger \\
1.23 \pm 0.12 \dagger\end{array}$ & $\begin{array}{l}2.26 \pm 0.07 \\
1.92 \pm 0.08 \\
1.21 \pm 0.10 \\
1.55 \pm 0.05\end{array}$ & $\begin{array}{l}2.29 \pm 0.08 \\
1.56 \pm 0.12 \ddagger \\
1.05 \pm 0.09 \\
1.32 \pm 0.065\end{array}$ \\
\hline $\begin{array}{l}\mathrm{C}_{3} \\
\mathrm{AM}_{4} \\
\mathrm{ACA} \\
\mathrm{MCA}\end{array}$ & $\begin{array}{l}2.31 \pm 0.11 \\
2.19 \pm 0.11 \\
1.02 \pm 0.06 \\
1.30 \pm 0.07\end{array}$ & $\begin{array}{r}2.41 \pm 0.11 \\
1.98 \pm 0.15 \\
0.97 \pm 0.14 \\
1.37 \pm 0.13 \\
\end{array}$ & $\begin{array}{l}2.48 \pm 0.15 \\
2.07 \pm 0.18 \\
0.98 \pm 0.12 \\
1.46 \pm 0.20\end{array}$ & $\begin{array}{l}2.42 \pm 0.14 \\
2.01 \pm 0.09 \\
1.18 \pm 0.16 \\
1.47 \pm 0.09 \\
\end{array}$ & $\begin{array}{l}2.28 \pm 0.17 \\
1.85 \pm 0.13 \\
1.27 \pm 0.06 \\
1.41 \pm 0.08 \\
\end{array}$ & $\begin{array}{l}2.30 \pm 0.11 \\
1.84 \pm 0.10 \\
1.20 \pm 0.05 \\
1.43 \pm 0.06\end{array}$ & $\begin{array}{l}2.22 \pm 0.03 \\
1.95 \pm 0.05 \\
1.22 \pm 0.08 \\
1.59 \pm 0.06 \\
\end{array}$ & $\begin{array}{l}2.36 \pm 0.07 \\
2.12 \pm 0.08 \\
1.15 \pm 0.11 \\
1.39 \pm 0.10 \\
\end{array}$ \\
\hline $\begin{array}{ll}x & \text { All } \\
\dagger & p \\
\ddagger & p \\
\text { s } & p\end{array}$ & $\begin{array}{l}1 \text { by } \\
91 \text { by }\end{array}$ & $\begin{array}{l}\text { eters a } \\
\text { st } \infty \mathrm{m} \\
\text { st } \infty \mathrm{m} \\
\text { test } \infty \mathrm{n}\end{array}$ & $\begin{array}{l}\text { neans } \pm \\
\text { Day } 0 \text { to } \\
\text { bay } 0 \text { to } \\
\text { Day } 0 \text { to }\end{array}$ & $\begin{array}{l}\text { idard } \\
7 . \\
7 . \\
7 .\end{array}$ & & 3 & if. 0 & ural ICA. \\
\hline
\end{tabular}

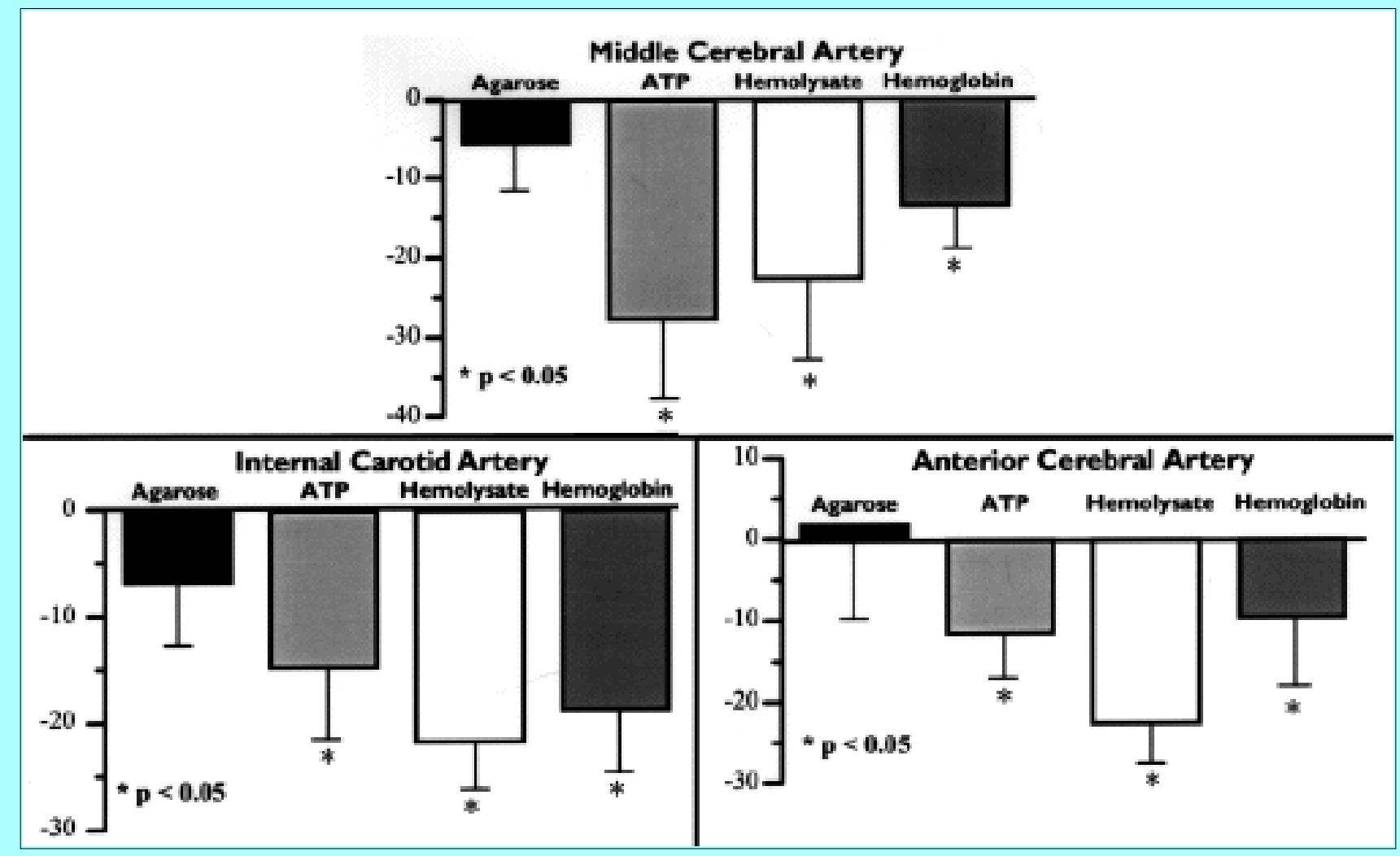

Fig. 1. Bar graphs showing the percentage change in MCA, ICA, and ACA diameters between Day 0 and Day 7 for each group. The bars represent the means \pm standard error of the means. Statistically significant reductions in diameters occurred in animals in every group except those exposed to agarose (paired t-tests).

\section{Angiographic Evaluation}

Comparisons within each group showed significant reductions in the right-sided cerebral arteries in animals exposed to ATP, hemolysate, or hemoglobin (paired t-tests, p < 0.05, Tables 2 and 3, Figs. 1-3). For the right MCA, diameters were reduced $28 \pm 7 \%$ for ATP, $23 \pm 7 \%$ for hemolysate, and $15 \pm 2 \%$ for hemoglobin. Seventeen (74\%) of 23 animals exposed to ATP, hemolysate, or hemoglobin developed vasospasm that was mild in $10(59 \%)$, moderate in six (35\%), and severe in one (6\%). There were no significant differences 
between groups in diameters of cerebral arteries on Day 7 (ANOVA).

\begin{tabular}{|c|c|c|c|c|}
\hline & ENTAGE OF CHAI & $\begin{array}{l}\text { TABLE } \\
\text { ANGOGRA PHI } \\
\text { TWEEN DAV } 0\end{array}$ & $\begin{array}{l}\text { YISUAL IZED ARTERI } \\
\text { OAV } 7^{\star}\end{array}$ & DIAMETER \\
\hline Antery & Agarose Group & ATP Group & Hemolysate Group & $\begin{array}{c}\text { Purified } \\
\text { HemodobinGroup }\end{array}$ \\
\hline right & & & & \\
\hline $\begin{array}{c}\mathrm{C}_{3} \\
\mathrm{C}_{4} \\
\mathrm{ACA} \\
\mathrm{MCA}\end{array}$ & $\begin{aligned}-0.9 & \pm 3 \\
-7.1 & \pm 7.2 \\
1.4 & \pm 10.6 \\
-6.3 & \pm 3.9\end{aligned}$ & $\begin{aligned}-3.4 & \pm 3.2 \\
-15.5 & \pm 5.7 \dagger \\
-13 & \pm 5.3 \dagger \\
-27.8 & \pm 6.7 \ddagger\end{aligned}$ & $\begin{array}{c}4.2 \pm 6 \\
-20.9 \pm 9.2 \dagger \\
-23.2 \pm 5.5 \ddagger \\
-22.7 \pm 7.3 \dagger\end{array}$ & $\begin{aligned} 1.8 & \pm 3.5 \\
-19 & \pm 5.1 \ddagger \\
-9.5 & \pm 11.2 \\
-15.3 & \pm 2.38\end{aligned}$ \\
\hline $\begin{array}{l}\mathrm{C}_{3} \\
\mathrm{ACA}_{4} \\
\mathrm{MCA}\end{array}$ & $\begin{array}{r}6.1 \pm 4.9 \\
-11.5 \pm 6.2 \\
11.1 \pm 8.5 \\
6.9 \pm 5.7\end{array}$ & $\begin{aligned}-2 & \pm 2.4 \\
-0.7 & \pm 5.1 \\
20.02 & \pm 12.4 \\
3.1 & \pm 7.3\end{aligned}$ & $\begin{aligned} 4.2 & \pm 9.1 \\
2.6 & \pm 11.4 \\
-6.6 & \pm 3.4 \\
4.8 & \pm 7.1\end{aligned}$ & $\begin{array}{r}6.4 \pm 3.6 \\
8.5 \pm 3.5 \\
-5.2 \pm 8.3 \\
-12 \pm 6.1\end{array}$ \\
\hline $\begin{array}{ll}x & \text { All we } \\
\dagger & p \times 0 \\
\ddagger & p<0 \\
\text { s } & p<0\end{array}$ & $\begin{array}{l}\text { leans } \pm \text { stand } \\
\text { t-test, comp } \\
\text { t-test, comp } \\
\text { d t-test, com }\end{array}$ & $\begin{array}{l}\text { or of the mear } \\
\text { ay } 0 \text { to Day? } \\
\text { ay } 0 \text { to Day? } \\
\text { Day to Day }\end{array}$ & Table 2 for abt & tions. \\
\hline
\end{tabular}
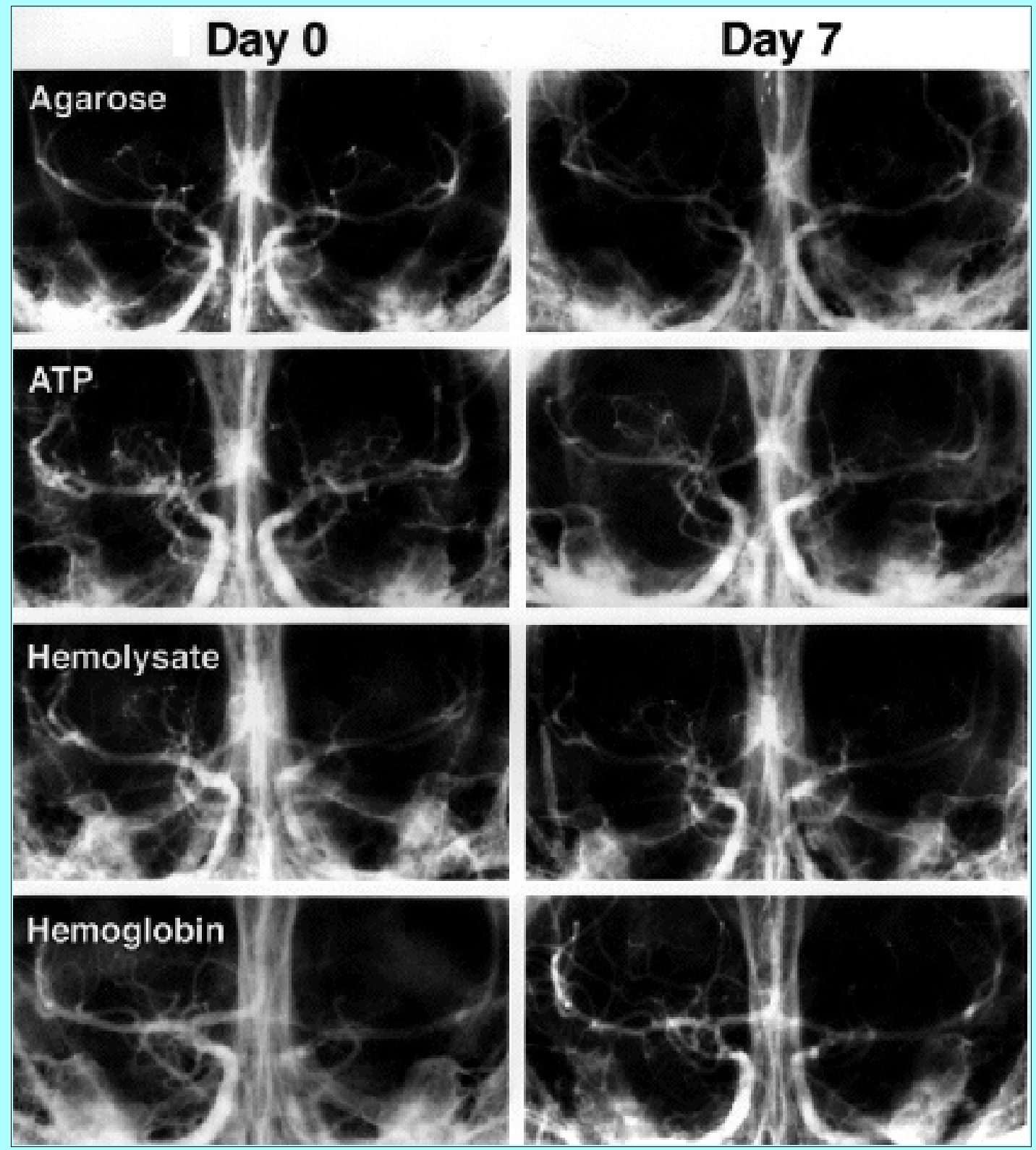
Fig. 2. Representative angiograms, Day 0 (left) and Day 7 (right), obtained in animals in the agarose (upper row), ATP (second row), hemolysate (third row), and hemoglobin (lower row) groups. There is narrowing of the right MCA in animals exposed to all compounds except agarose.

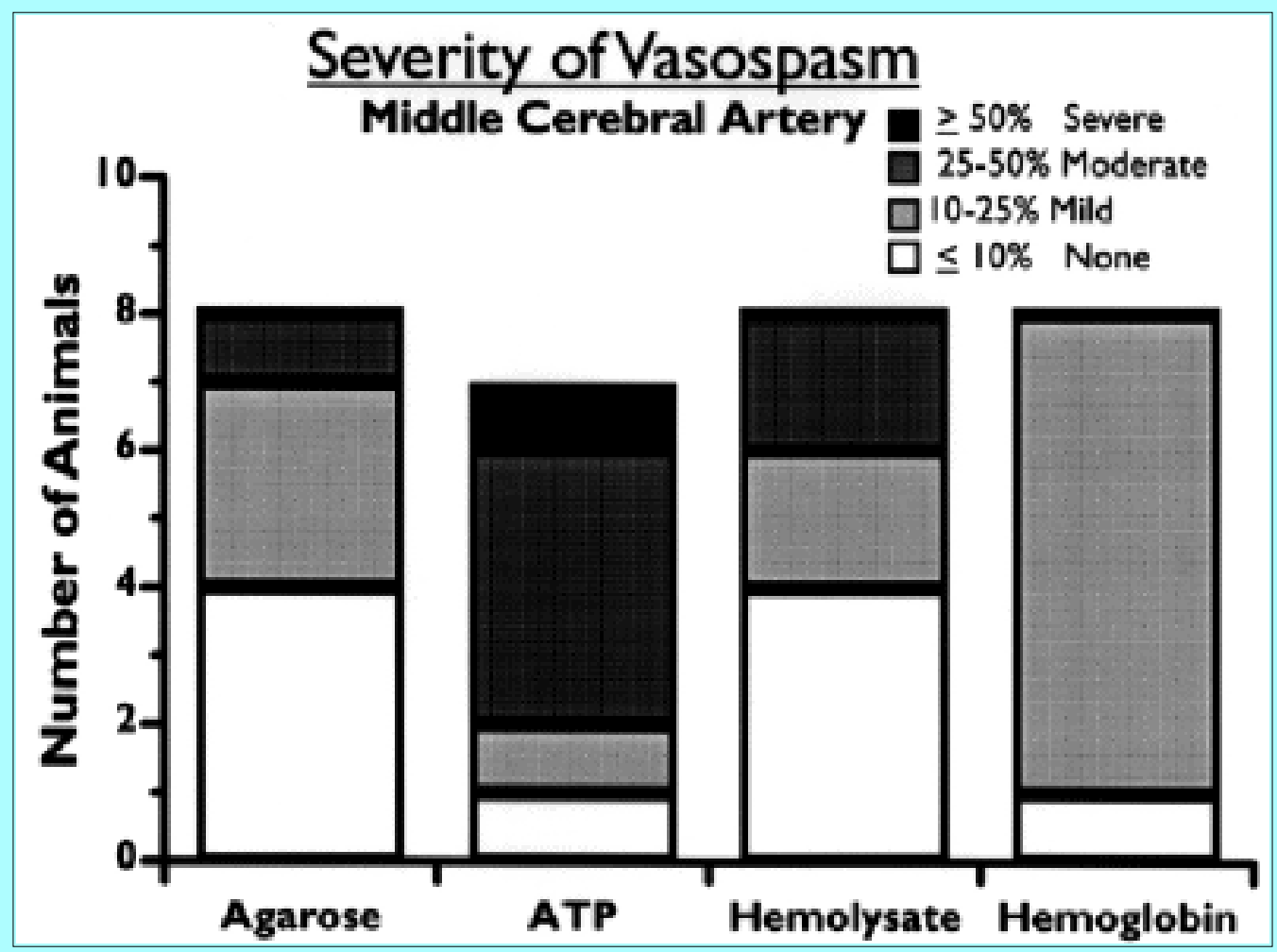

Fig. 3. Bar graph displaying numbers of animals in each group and the severity of vasospastic response to various compounds.

\section{Adenine Nucleotide Concentrations}

The concentration of ATP in subarachnoid agarose in the ATP group decreased approximately 60 -fold to a basal level that was similar to that found in the agarose alone group. Concentrations of ATP were highest on Day 7 in animals exposed to hemoglobin (ANOVA, p < 0.05, Fig. 4). Levels of ADP and AMP were highest in animals exposed to hemolysate or hemoglobin (ANOVA, $p<0.05$; Fig. 4). 


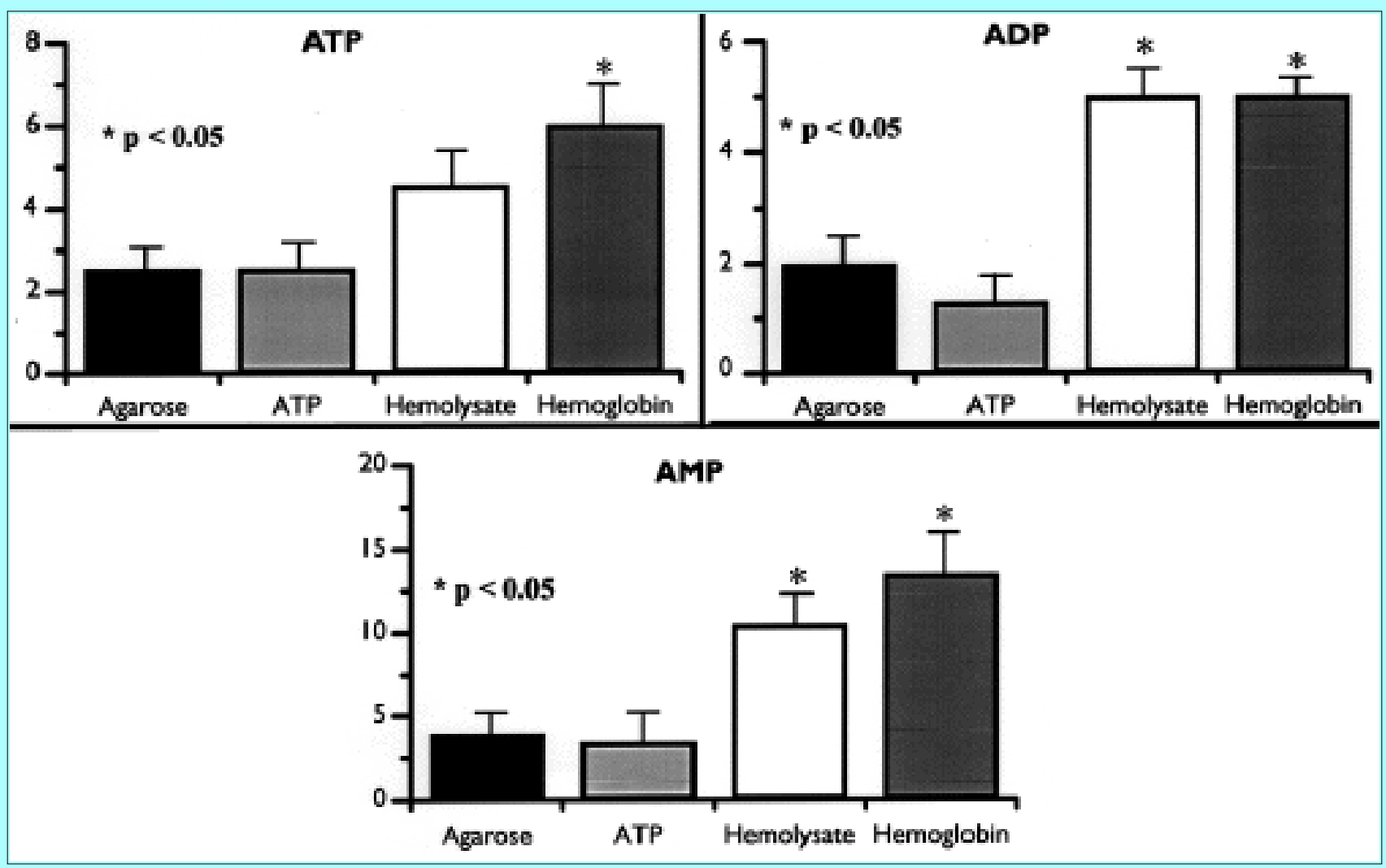

Fig. 4. Bar graphs showing concentrations of ATP, ADP, AMP remaining in the subarachnoid agarose removed on Day 7 for each group. The bars represent the means \pm standard error of the means. There was significantly more ATP, ADP, and AMP in the subarachnoid agarose removed from animals in the hemoglobin group (ANOVA) and ADP and AMP in the subarachnoid agarose removed from animals in the hemolysate group (ANOVA).

\section{Pathological Examination}

Pathological examination showed only very mild inflammation in the subarachnoid spaces of animals exposed to hemolysate or hemoglobin. The results suggested that there was more inflammation in these groups compared with animals exposed to ATP or agarose, although this was not statistically significant (Table 4, Fig. 5). Endothelial proliferation and smooth-muscle necrosis were not observed and are not tabulated.

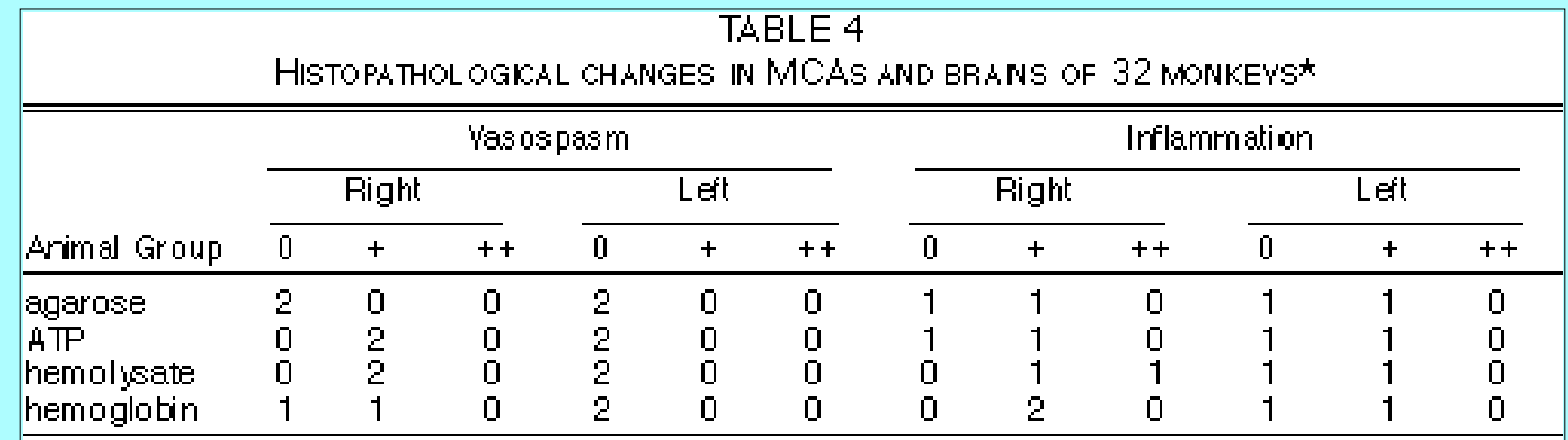

"Two MCAs in each group mere evaluated. The degree of inflammation was graded on a 3-point scale by an investigator blinded to animal's group. $0=$ none; $+=$ mild; and $++=$ moderate. 


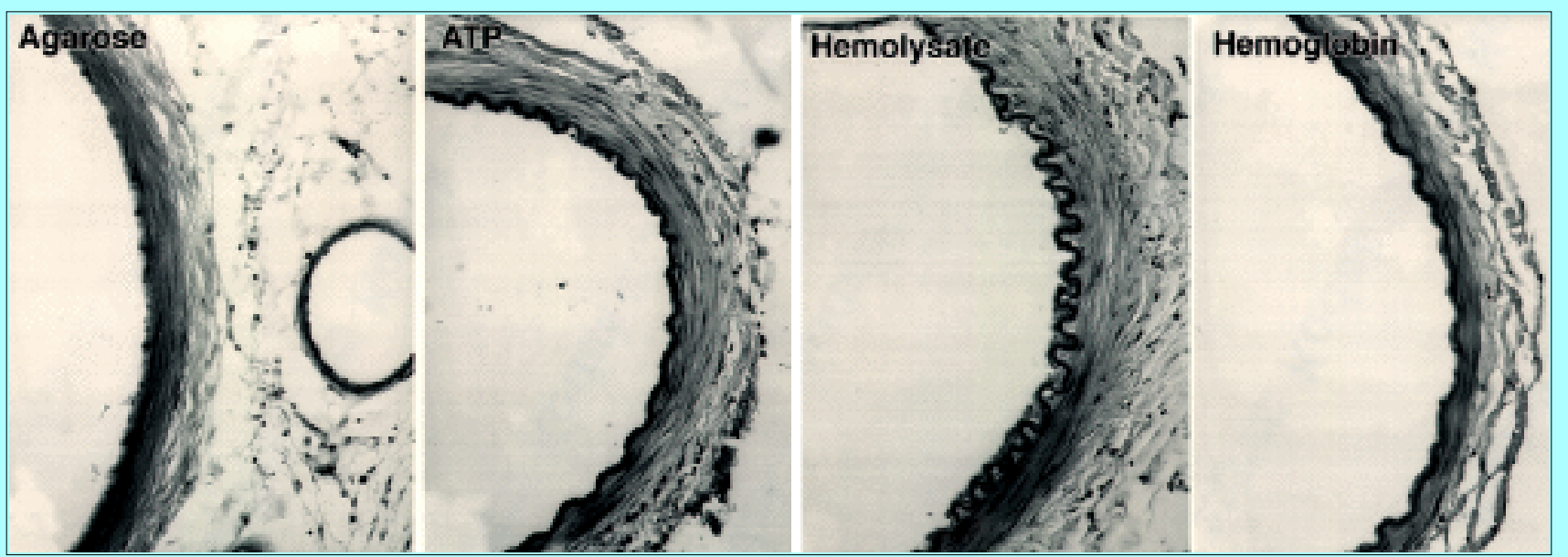

Fig. 5. Photomicrographs of histopathological sections of MCAs obtained in animals exposed to agarose, ATP, hemolysate, or hemoglobin. The arteries exposed to ATP, hemolysate, or hemoglobin show corrugation of the internal elastic lamina consistent with contraction and vasospasm but show no other histopathological changes such as smooth-muscle cell necrosis or endothelial proliferation. H \& E, original magnification X 100.

\section{DISCUSSION}

Shirahase, et al.,[17] described endothelium-dependent contractions in the BAs of dogs in response to hemolysate and cerebrospinal fluid taken from patients with SAH. Adenosine triphosphate produced the same effect and was present in high concentrations in hemolysate. The authors postulated that ATP is involved in vasospasm. Zhang and colleagues[25,26] also suggested that ATP may be important in vasospasm based on their findings that: 1) the compound in fresh hemolysate that increased $\left[\mathrm{Ca}^{++}\right]_{\mathrm{i}}$ in cerebrovascular smooth muscle and endothelial cells was of a similar molecular weight to ATP; and 2) the increases in $\mathrm{Ca}^{++}$could be blocked by antagonists of $\mathrm{P}_{2}$-purinoceptors, the receptors on which ATP acts. Because hemolysis and smooth-muscle contraction secondary to increased $\left[\mathrm{Ca}^{++}\right]_{\mathrm{i}}$ are believed to be important in vasospasm, it follows that ATP might be important. The question has not been investigated by using in vivo experiments, except for a study in which it was shown that injection of ATP into the dog BA, minutes after a single SAH, aggravated acute vasospasm.[4] Although ATP acts on cell surface receptors to mediate physiological processes $[2,5,13,15,16]$ and physiological agonist-receptor interactions have not usually been thought to characterize the pathological arterial narrowing of vasospasm, it was believed to be worth investigating because of discrepancies in the theory that hemoglobin causes vasospasm.[18,25]

The literature suggesting that hemoglobin--specifically, OxyHb--is the major cause of vasospasm has been reviewed,[8] but there are several inconsistencies in this theory. Hemoglobin increased $\left[\mathrm{Ca}^{++}\right]_{\mathrm{i}}$ levels in isolated smooth-muscle cells in some studies.[20-23] In some cases, however, impure solutions of hemoglobin were used, raising the possibility that other substances may have produced the observed effects or acted with hemoglobin to produce them. Pure hemoglobin did not increase $\left[\mathrm{Ca}^{++}\right]_{\mathrm{i}}$ in rat BA smooth-muscle cells assessed by using a sensitive and accurate $\mathrm{Ca}^{++}$imaging system.[25] Isometric tension studies suggested that hemoglobin must act together with low-molecular -weight substances to produce maximum contractions.[1] Injections or placement of $\mathrm{OxyHb}$ in the subarachnoid space of monkeys produced vasospasm, but this was generally not as severe as that produced by whole blood.[9,10] Whole blood usually causes a 50\% reduction in MCA diameter and is associated with some degree of damage to the smooth-muscle cells that is evident histopathologically. No compound tested in this study caused these changes. 
The results of this study demonstrate that ATP and pure hemoglobin produce significant reductions in the diameter of the right cerebral arteries 7 days after placement in the subarachnoid space of monkeys. The vasospasm produced is less severe than that which develops in response to a blood clot containing the same amount of ATP or hemoglobin. In addition, hemolysate that contains both ATP and hemoglobin produced the same degree of vasospasm. There was no synergistic increase when both compounds were present. The amount of ATP in hemolysate, however, was approximately 10-fold less than that used in the ATP group. This concentration in vitro produced a contraction similar to the higher concentration, although the nature of the dose-response curve in vivo is not known and renders such a comparison subject to dispute.[18] None of the compounds produced histopathological changes in the narrowed arteries. Several explanations are possible. Compounds other than those tested may be responsible for vasospasm after blood clot placement. More complex interactions among combinations of compounds, such as ATP plus hemoglobin combined with other substances, may also be involved. Finally, because severe vasospasm was not reliably produced in any group in this experiment, it is possible that ATP and/or hemoglobin may cause vasospasm but that the method by which they are delivered does not release the compounds in a way that is necessary for severe vasospasm to develop. This argument has been used previously to account for results showing that although erythrocytic cytosol seems to be the only blood component that causes vasospasm in vivo, it does not produce as much vasospasm as whole blood in the same model.[11,14] Unless experiments demonstrate consistent and severe vasospasm in response to isolated spasmogens, the possibility cannot be ruled out that other compounds or processes induced by them were removed in the isolation of hemolysate or hemoglobin.

It is unlikely that severe vasospasm was present earlier than 7 days because histopathological changes in the arteries would certainly still be present. Adenine nucleotide levels were low by Day 7 when the subarachnoid agarose was analyzed. Adenine nucleotide concentrations in agarose at Day 7 were highest in those originally containing hemoglobin or hemolysate. This may be because there was more inflammation in the subarachnoid space in these animals and inflammatory cells that contain and can release adenine nucleotides may have invaded the agarose.[19]

\section{CONCLUSIONS}

These results suggest that ATP may be involved in the pathogenesis of vasospasm. Because ATP may be rapidly degraded in vivo, measurements of the concentration of ATP in the subarachnoid space next to vasospastic cerebral arteries and correlation of such changes with vasospasm need to be made. Further work is necessary to define accurately the substances in subarachnoid clot that cause vasospasm.

\section{References}

1. Aoki T, Takenaka K, Suzuki, et al: The role of hemolysate in the facilitation of oxyhemoglobin-induced contraction in rabbit basilar arteries. J Neurosurg 81:261-266, 1994

2. Boarder MR, Weisman GA, Turner JT, et al: G protein-coupled $\mathrm{P}_{2}$ purinoceptors: from molecular biology to functional responses. Trends Pharmacol Sci 16:133-139, 1995

3. Everse J, Hsia N: The toxicities of native and modified hemoglobins. Free Rad Biol Med 22:1075-1099, 1997

4. Haciyakupoglu S, Kaya M, Cetinalp E, et al: Effect of prostacyclin and adenosine triphosphate on vasospasm of canine basilar artery. Surg Neurol 24:126-140, 1985

5. Hardebo JE, Kahrstrom J, Owman C: P1 and $\mathrm{P}_{2}$-purine receptors in brain circulation. Eur J Pharmacol 144:343-352, 1987 
6. Hayman LA, Taber KH, Ford JJ, et al: Mechanisms of MR signal alteration by acute intracerebral blood: old concepts and new theories. AJNR 12:899-907, 1991

7. Hino A, Weir BKA, Macdonald RL, et al: Prospective, randomized, double-blind trial of BQ-123 and bosentan for prevention of vasospasm following subarachnoid hemorrhage in monkeys. J Neurosurg 83:503-509, 1995

8. Macdonald RL, Weir B: A review of hemoglobin and the pathogenesis of cerebral vasospasm. Stroke 22:971-982, 1991

9. Macdonald RL, Weir BKA, Runzer TD, et al: Effect of intrathecal superoxide dismutase and catalase on oxyhemoglobin-induced vasospasm in monkeys. Neurosurgery 30:529-539, 1992

10. Macdonald RL, Weir BKA, Runzer TD, et al: Etiology of cerebral vasospasm in primates. J Neurosurg 75:415-424, 1991

11. Mayberg MR, Okada T, Bark DH: The role of hemoglobin in arterial narrowing after subarachnoid hemorrhage. J Neurosurg 72:634-640, 1990

12. Minetti MC, Mallozzi C, Scorza G,, et al: Role of oxygen and carbon radicals in hemoglobin oxidation. Arch Biochem Biophys 302:233-244, 1993

13. Muramatsu I, Kigoshi S: Purinergic and non-purinergic innervation in the cerebral arteries of the dog. $\mathbf{B r}$ J Pharmacol 92:901-908, 1987

14. Nozaki K, Okamoto S, Yanamoto H, et al: Red blood cells are essential for late vasospasm following experimentally induced subarachnoid hemorrhage in dogs. Neurol Med Chir 30:10-15, 1990

15. Olsson RA, Pearson JD: Cardiovascular purinoceptors. Physiol Rev 70:761-845, 1990

16. Ralevic V, Burnstock G: Roles of $\mathrm{P}_{2}$-purinoceptors in the cardiovascular system. Circulation 84:1-14, 1991

17. Shirahase H, Usui H, Manabe K, et al: Endothelium-dependent contraction and -independent relaxation induced by adenine nucleotides and nucleoside in the canine basilar artery. J Pharmacol Exp Ther 247:1152-1157, 1988

18. Sima B, Macdonald L, Marton LS, et al: Effect of $\mathrm{P}_{2}$-purinoceptor antagonists on hemolysate-induced and adenosine 5'-triphosphate-induced contractions of dog basilar artery in vitro. Neurosurgery 39:815-822, 1996

19. Suprenant A, Rassendren F, Kawahima E, et al: The cytolytic $P_{2 Z}$ receptor for extracellular ATP identified as a $\mathrm{P}_{2 \mathrm{X}}$ receptor $\left(\mathrm{P} 2 \mathrm{X}_{7}\right)$. Science 272:735-738, 1996

20. Takanashi Y, Fujitsu K, Fujii S, et al: Altered reactivity of hemolysate-treated cultured smooth-muscle cells from rabbit basilar artery determined by digital imaging microscopy. J Neurosurg 75:82-90, 1991

21. Takanashi Y, Weir BKA, Vollrath B, et al: Time course of changes in concentration of intracellular free calcium in cultured cerebrovascular smooth muscle cells exposed to oxyhemoglobin. Neurosurgery 30:346-350, 1992

22. Takenaka K, Yamada H, Sakai N, et al: Cytosolic calcium changes in cultured rat aortic smooth-muscle 
cells induced by oxyhemoglobin. J Neurosurg 74:620-624, 1991

23. Takenaka K, Yamada H, Sakai N, et al: Intracellular $\mathrm{Ca}^{2+}$ changes in cultured vascular smooth muscle cells by treatment with various spasmogens. Neurol Res 13:168-172, 1991

24. Traut TW: Physiological concentrations of purines and pyrimidines. Mol Cell Biochem 140:1-22, 1994

25. Zhang H, Weir B, Marton LS, et al: Mechanisms of hemolysate-induced $\left[\mathrm{Ca}^{2+}\right]_{\mathrm{i}}$ elevation in cerebral smooth muscle cells. Am J Physiol 269:H1874-H1890, 1995

26. Zhang H, Weir BKA, Macdonald RL, et al: Mechanisms of $\left[\mathrm{Ca}^{2+}\right]_{\mathrm{i}}$ elevation induced by erythrocyte components in endothelial cells. J Pharmacol Exp Ther 277:1501-1509, 1996

Manuscript received August 22, 1997.

Accepted in final form September 17, 1997.

This work was supported by grants from the National Institutes of Health to Dr. Macdonald (K08 NS01831) and Dr. Weir (NS25946). Dr. Macdonald is supported by an American College of Surgeons Faculty Fellowship and a Young Clinician Investigator Award from the American Association of Neurological Surgeons.

Address reprint requests to: R. Loch Macdonald, M.D., Section of Neurosurgery, MC3026, University of Chicago Medical Center, 5841 South Maryland Avenue, Chicago, Illinois 60637. email: lmacdona@surgery.bsd.uchicago.edu. 